M.R.C.S.Eng., Cambridge University and St. Bartholomew's Bospital . F. W. F. Ross, M.D., C.M.Edin., M.R.C.S.Eng. L.R.C.P.Lond., Edinburgh University and University College, London. C. W' Rowntree, M.B.Lond., M.R.C.S.Eng
Hospital : W. A.C.C. S.Lond., Middiesex
H. Scott, M.B.Toronto, M.R.C.S.Eng., L.R.C.P.Lond. Hospital W. W. Scott, M.B.Toronto, M.R.C.S.Eng., L.R.C.P.Lond.
Toronto University, University and King's Colleges, London; G. S. Thompson, St. Mary's Hospital; C. F W Walters, M.R.C.S.Eng., L.R.C.P.Lond. University College, Bristol, and King. College,
London: A. J. Walton, London Hospital; and P. R. Wrightly, M.R.C. S.Eng., L.R.C.P.Lond., Owens College, Manchester. One hundred and twenty-eight candidates presented themselves for
this examination, of whom 49 passed, and 79 were referred.

Erratux.- In the list of members of the Council of the College of placed instead of "Sir" before the name of Alfred Cooper.

TRINITY COLLEGE, DUBLIN.

THe following candidates have passed the Final Examination in Midwifery:

. L. Middleton, W. Wiley, J. F. W. Leech, J. M. Holmes, J. F. Nicholson, E. V. Collen, H. stokes. W. Boxwell, H. O'H. May, R. W. T.
Clampett, T. Crean, A. B. Tighe, R. Bailey, J. T. M'Entire, A. L. Otway.

\section{PUBLIC HEALTH AND}

\section{POOR-LAW MEDICAL SERVICES.}

\section{POOR-LAW MEDICAL OFFICERS' ASSOCIATION OF ENGLAND AND WALES.}

THe annual general meeting of this Association will take place on Tuesday, June 3 oth, at the Trocadero, Regent Street, W., at 6.30 p.m. At 7.30 the members and their friends will dine together, Dr. Farquharson, M.P., the President, being in the chair. Any Poor-law medical officer wishing to be present is requested to communicate with the Honorary Secretary, Dr. M. Greenwood, 9, Copthall Avenue, London Wall, E.C.

\section{HEALTH OF KNGISB TOWNS}

IN seventy-six of the largest English towns, including London, 7,738 births and 4 , 45 deaths were registered during the week ending saturdasy
last, June 6 th. The annual rate of mortality in these towns, whicn had last, June 6th. The annual rate of mortality in these towns, whicn had been $15.4,15.5$, and 14.9 per $\mathrm{x}, 000$ in the three preceding weeks, further
declined to 14.3 per $\mathrm{x}, 000$ last week. The rates in the several towns ranged declined to 14.3 per 1,000 last week. The rates in the several towns ranged
from 6.4 in Walthamstow, 6.9 in Reading, 7.x in Burton-on-Trent, 8.0 in from 6.4 in Waithamstow, 6.9 in Reading, 7.I in Burton-on-Trent, 8.0 in 10.9 in Liverpool, 20.6 in Bury, $2 x$. 0 in Wigan, 21.3 in South shields, 22 o in Warrington, 22.6 in Handsworth, 22.8 in Preston, 234 in Rochdale, and 29.1 in Middlesbrough. In London the rate of mortality was 13.8 per x,ooo, while it averaged 14.6 per $x, 00$ in the seventy-five other large
towns. The death-rate from the principal infectious diseases averaged x.4 per $x, 000$ in the seventy-six large towns; in London this death-rate was equal to $x .5$ per $x, 000$, while it averaged $x .3$ in the seventy-five other large towns, among which the highest death-rates from the principal coting deases were $3 \circ$ in brough, and 3.4 in Wigan. Measles caused a death.rate of $x .1$ in Nottingham, $\mathrm{x.2}$ in Bolton and in Sheffield. $\mathrm{I} .4$ in East $\mathrm{Ham}, \mathrm{x} .6$ in Wolverhampton, 2.2 in Coventry and in Middlesbrough, and 34 in Wigan, and
whooping-cough of I.. in Croydon and in Swansea, 1.5 in Merthyr Tydfil, and 18 in Preston. The mortality from scarlet fever, from diphtheria, large towns. Two fatal cases of small-pox were registered in Manlarge towns. Two fatal cases of small-pox were registered in Mannot one in any other of the seventy-six large towns. The number of not one in any other of sever sin the Metropoiltan Asylums Hospitals which had been 60,64 , and 60 at the end of the three preceding weeks, had risen again to 72 at the end of last week; 24 new cases were admtted during the week, against 7 , 19, and ro in the three preceding weeks. The number of scarlet fever patients in these hospitals and in the London Fever Hospital on Saturday, the 6th inst., was 1,785, against numbers increasing from $1,66_{12}$ to 1,771 on the seven preceding saturdays; 210 new cases were admitted during the week, against 236, 234, and 225 in the three preceding weeks.

HEALTH OF SCOTCH TOWNS.

DURING the week ending Saturday last, June 6 th, r, 108 births and 596 deaths were registered in eight of the principal scotch towns. Tne 18.4 per $x, 000$ in the three preceding weeks, declined again last woek to 18.2 per $x, \infty 00$, but was 3.9 per $x, 000$ above the mean rate during the same period in the seventy-s1x large English towns. The rates in the oight Scotch towns ranged from 10.8 in Perth and 15.1 in Paisley to 18.8 in Greenock and 19.1 in Glasgow and in Edinburgh. The death-rate trom the principal lufectious diseases averaged 2.0 per r,o00 in these 6 from diarrhoea, 5 from scarlet fever, 4 from measles, and 2 from diph: theria. Bix fatal cases of diphtheria, 5 of whooping-cough and 4 of measles were recorded in Kdinburgh; 5 of diarrhoea in Aberdeen, and 3 of whooping-cough in Greenock.

\section{HEALTH OF IRISH TOWNS.}

DURING the week ending Saturday last, June 6 th, 589 births and 33 deaths were registered in six of the principal irish towns. The mean annual wato res. being $x .9$ above the mean rate during the same period in the seventy-six large English towns. The death.rates ranged in these six Irish towns from 6.8 in Limerick, and 7.8 in Waterford, to 21.4 in Londonderry, and 24.4 in Dublin. The death-rate in the six towns from the principal zymotic diseases averaged r.3 per r,ooo, the highest rates being recorded
in Londonderry and Waterford. The deaths registered in Dublin included 3 which were referred to small-pox, 2 to measles, I to whoopingcough, 3 to enteric, and x to diarrhoea. No deaths from small-pox occurred elsewhere, but Belfast recorded 2 deaths from measles and whooping-cough. Limerick had no deaths from zymotic disease at all.

SMALL-POX AT SOUTHEND.

DR. NASH, M.O.H. Southend, informs us that only one case of small-pox was notified in Southend during the week ending May 30 oth, and not three as printed last week.

\section{MEDICAL NEWS,}

THe Earl of Derby, who is President of the Brompton Consumption Hospital, has contributed $f_{I}, 000$ to the funds of the country branch of the hospital for the open-air treatment of consumption which is now being erected at Heatherside, near Frimley.

THE first general meeting of the Belgian National League against tuberculosis will be held at Brussels on Sunday, June 14th. An address on Tuberculosis as a Social Disease will be delivered by Professor Calmette, Director of the Pasteur Institute, Lille.

Presentation.-Dr. George A. Davies, J.P.. of Newport, Mon., was recently presented with a diamond ring and a silver tea-set, kettle, and tea-cadd 7 by his numerous friends and old patients, on the occasion of his retiring, aiter 30 years' practice in Newport, on account of ill-health. The testimonial was accompanied with expressions of appreciation of his professional ability, esteem for his personal character, and a desire for his speedy recovery.

\section{MEDICAL VACANCIES.}

This list of vacancies is compiled from our adverlisement columns, where full particulars will be found. To ensure notice in this column advertisements post on Wednesday morning.

AYLESBUR Y: ROYAL BUCKINGBAMSHIRE HOSPITAL-Resident Surgeon. BARNSLEY: BECKETT IMOSPITAL.- Resident House-Surgeon. Salary, \&100 per BIRK ENHEAD BOROUGH HOSPITAL.--Junior Male House-Surgeon, resident. Salary, BIRMINGHAM GENERAL DISPENSARY.-Three Qualified Resident Locums. Terms, 4 guineas per week.
BIRMINGHAM GENERAL HOSPITAL-House-Surgeon, resident. Salary at the rate of \&50 per annum.

CANTBRBURY: KENT AND CANTERBURY HUSPITAL.-House Surgeon, resident. CHESTER GEN ERAL INFIRMARY.-House Physiclan, resident. Salary, 290 per DODLEY: GUEST HOSPITAL.-Assistant House-Surgeon, resident. Salary at the DUNDEE COMBINATION EAST POORHOUSE AND HOSPITAL-Resident Medica? EVELINA HOSPITAL FOR SICK CHILDREN, Southwark.-Four Qualified Clinical Assistants ; also Uniualified Clinical Clerks in the uut-patienc Department.
GUILDFORD: ROYAL SURREY COUNTY HOSPTTAL-Resident House-Surgeon. HOSPITAL FOR WOMEN, Soho Square, W.-House-Physician. Appointment for air IIVERPOOL: STANLEY HOSPITAL.-Third House-Surgeon, resident. Salary, \&7\% LONDON HOSPITAL MEDICAL COLLEGE, Mile End.-(1) Demonstrator of Chemical Physiology. Salary, t2200 per annum. (2) Lectureship on B.ology. Salary, \&100 per WONDON SOHOOL OF MEDICINE POR WOMEN, Hunter Street, W.C.-Second NEWCASTLE-ON-TYNE DISPENSARY.-Visiting Medical Assistant. Salary, £160 for

NEW PORT AND MON MOUTHSHIRE HOSPITAL-Assistant House-Surgeon, resident. NORTH, STAFPORDYHIRE INFIRMARY, Harts'.1l.- House-Phys:cian, resident.

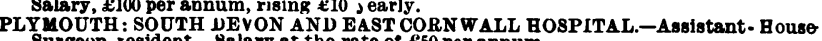
RYDurgeun, resident. Aalary at the rate of E50 per annum. ST. MAtY'S HuSpITal MEdical SCHOOL, Paddington.-Lecturer on Physiology. SHEFFIELLD ROY RLL HOSPITAL.-Junior Assistant House-Surgeon, resident. Salary, soUTHAMPTUN COUNTY BOROUGH.-Assistant to the Medical Offoer of Health.

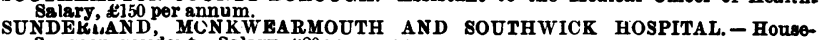

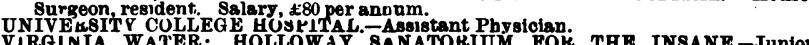

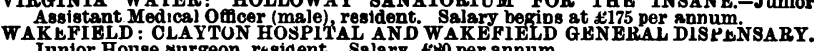
Junior House surgeon, rrsiaent. Salary. E⿺辶 per annum.
WAREINGTON INFIRMARY AND DISPENSARY.-Senior Resident House-Surgeon.

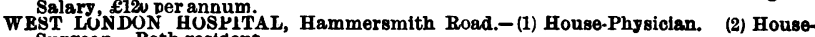
WIGAN: ROYAL ALBERT EDWARD INFIRMARY.-Senior House-Surgeon, resident. WOLVERHAMPTON AND STAFFORDSHIRE GENERAL HOSPITAL. - HouseYORK DISPENSA Y Y. $-R=$ saeent Medical Othcer. Sulary, $£ 120$ per annum.

CORRBCTIONS. - In the list of vacancies published last week it should have been stated

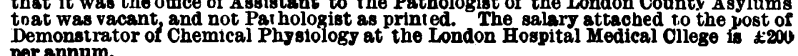

